\title{
USO IRRACIONAL E RESISTÊNCIA A ANTIMICROBIANOS EM HOSPITAIS
}

\author{
Priscila Noemi Vieira ${ }^{1}$ \\ Suellen Lais Vicentino Vieira²
}

VIEIRA, P. N.; VIEIRA, S. L. V. Uso irracional e resistência a antimicrobianos em hospitais. Arq. Cienc. Saúde UNIPAR, Umuarama, v. 21, n. 3, p, 209-212, set./dez. 2017.

\begin{abstract}
RESUMO: Os antimicrobianos são uma das classes de medicamentos mais prescritas em todo o mundo. São utilizados para inibir ou combater o crescimento de determinados microrganismos, mas quando são indicados sem necessidade ou com imprecisão, facilitam o desenvolvimento da resistência bacteriana. Atualmente, os antimicrobianos estão entre os fármacos mais prescritos em hospitais, e uma das consequências mais importantes do uso indiscriminado é a resistência bacteriana. Visando contribuir com medidas que facilitem o controle do problema, este trabalho teve como objetivo, analisar o uso racional de antimicrobianos e a resistência bacteriana em hospitais, através de estudo bibliográfico. As causas que levam a não efetividade de tratamento com antimicrobiano se deve a diversos fatores como, prescrição inadequada, erro na dose, posologia e/ou tempo de tratamento, escolha inapropriada, entre outros. Medidas preventivas devem ser tomadas, como conscientização dos prescritores, determinação de protocolos e cursos de atualização, bem como uma maior fiscalização dos órgãos competentes e comissões atuante nesta área como a CCIH.
\end{abstract}

PALAVRAS-CHAVE: Antimicrobiano. Resistência Bacteriana. Uso racional de antimicrobianos.

\section{IRRATIONAL USE OF ANTIMICROBIALS AND RESISTANCE IN HOSPITALS}

ABSTRACT: Antimicrobials are one of the most widely prescribed drug classes in the world. They are used to inhibit or combat the growth of some microorganisms, but if prescribed unnecessarily or inaccurately, they can help develop bacterial resistance. Currently, antimicrobials are among the most prescribed drugs in hospitals, and one of the most important consequences of its indiscriminate use is bacterial resistance. This paper aimed to analyze the rational use of antimicrobials and the bacterial resistance in hospitals by carrying out a bibliographic review. There are several factors that lead to non-effective antimicrobial treatments, among them unsuitable prescribing, dosage, treatment time, inappropriate choice of drugs. Preventive measures should be taken, such as awareness of prescribers, definition of protocols and refresher courses, as well as greater oversight of relevant bodies and committees acting in this area such as CCIH.

KEYWORDS: Antimicrobial. Bacterial resistance. Rational use of antimicrobials.

\section{Introdução}

Os antimicrobianos são fármacos de origem natural, semissintética ou sintética, com a propriedade de suprimir o crescimento dos patógenos ou destruí-los, e sua utilização na prática clínica modificou o curso natural, melhorando o prognóstico das doenças infecciosas, que são combatidas com a utilização desses medicamentos. Seu uso inadequado é uma das principais preocupações mundiais (ROGRIGUES; BERTOLDI, 2010, CARNEIRO et al., 2011), do qual nos últimos anos, foi constatado o aumento da prevalência da resistência bacteriana aos antimicrobianos disponíveis clinicamente, tornando-se uma grande preocupação para a saúde pública (DEL FIOL et al., 2010).

Desde a introdução do mais antigo antimicrobiano até o mais recente, nota-se que o equilíbrio existente entre o homem e as bactérias tem sido alterado pelo uso irracional e indiscriminado dessas drogas (FERRAREZE et al., 2007, MACHADO-ALBA; GONZALES-SANTOS, 2009), podendo os micro-organismos apresentar mecanismos de resistências intrínsecos e extrínsecos.

O termo resistente se refere a aqueles micro-organismos cujo crescimento e multiplicação não se inibem pelas concentrações habitualmente alcançadas no sangue ou tecidos do correspondente antimicrobiano, ou aqueles que apresentam mecanismos de resistência específicos para o agente estudado ao qual não havia uma adequada resposta clínica quando usado como tratamento. A resistência microbiana pode ser transferida por mecanismos diversos, podendo esta- belecer-se entre micro-organismos de uma mesma população ou diferentes populações (MOTA et al., 2005).

Atualmente, os antimicrobianos estão entre os fármacos mais prescritos em hospitais (JACOBY, 2008). Cerca de $25 \%$ a $35 \%$ dos pacientes hospitalizados recebem antimicrobianos, tanto para indicações terapêuticas como profiláticas, durante o internamento. Sendo estimado, que mais de $50 \%$ das prescrições são inadequadas, tanto na via de administração, na dose e duração do tratamento, bem como na indicação do fármaco (ONZI; HOFFMAN; CAMARGO, 2011).

No ambiente hospitalar, uma das consequências mais importante do uso indiscriminado de antimicrobianos é a resistência bacteriana, do qual a terapia antimicrobiana é rotineira, e as cepas multirresistentes são selecionadas e propagadas com mais facilidade (ROCHA; CARNEIRO; CASTILHO, 2009). Além de afetar o paciente que o utiliza, atinge também a microbiota ambiental do hospital, contribuindo com o aumento da morbidade, mortalidade, prolongamento no tempo de internação e provocando a elevação nos custos do tratamento (CARNEIRO et al., 2011). No campo econômico, a resistência bacteriana afeta de forma diferente os diversos envolvidos na utilização dessas drogas. O prescritor perde pacientes devido à ineficácia do tratamento; o paciente tem o curso da doença não solucionada, necessitando de fármacos alternativos, muitas vezes de custos mais elevados (RODRIGUES; BERTOLDI, 2010).

Em função deste quadro, é de grande interesse a realização de estudos sobre utilização de antimicrobianos que

DOI: 10.25110 /arqsaude.v21i3.2017.6130

${ }^{1}$ Farmacêutica Generalista, Especialista em Farmacologia Aplicada à Clínica e Terapêutica pela Universidade Paranaense - UNIPAR, Umuarama, PR, BR. ${ }^{2}$ Farmacêutica Bioquímica, Especialista em Docência e Gestão do Ensino Superior, Especialista em Farmácia Magistral com Ênfase em Cosmetologia e Dermocosméticos, Mestra em Biociências e Fisiopatologia, Doutoranda em Biociências e Fisiopatologia pela Universidade Estadual de Maringá - UEM Maringá, PR, BR, Docente da Universidade Paranaense - UNIPAR, campus sede, Umuarama, PR, BR. 
permitam detectar problemas neles. Visando contribuir com medidas que facilite o controle do problema, este trabalho teve o objetivo de analisar o uso racional de antimicrobianos e a resistência bacteriana em hospitais, por meio de um estudo bibliográfico.

\section{Desenvolvimento}

Os antimicrobianos são uma das classes de medicamentos mais prescrita mundialmente. São utilizados para inibir ou combater o crescimento de determinados micro-organismos, porém, muitas vezes são indicados sem necessidade ou com imprecisão, facilitando o desenvolvimento de resistência bacteriana e, consequentemente impedindo a ação de outros medicamentos (KADOSAKI; SOUSA; BORGES, 2012).

O mecanismo de resistência bacteriana mais importante e frequente é a degradação do antimicrobiano por enzimas, como as $\beta$-lactamases. Estas hidrolisam a ligação amida do anel dos antibióticos das classes dos beta-lactâmicos, destruindo, assim, o local onde os antimicrobianos ligam-se às proteínas de ligação da penicilina (PBP) e através do qual exercem seu efeito antibacteriano. Essas enzimas são codificadas em cromossomos ou sítios extracromossômicos através de plasmídeos ou transposons, podendo ser produzidas de modo constitutivo ou ser induzido. Outro mecanismo de resistência importante e comum é a alteração do local-alvo onde atua determinado antimicrobiano, impedindo a ocorrência de qualquer efeito inibitório ou bactericida. As bactérias podem adquirir um gene que codifica um novo produto resistente ao antibiótico, substituindo o alvo original. A resistência por bomba de efluxo também é uma forma da qual a bactéria impede a ação adequada do antibiótico, do qual a droga é retirada do interior da célula, através do bombeamento ativo do meio intracelular para o extracelular (ANVISA, 2007). A resistência bacteriana pode levar a infecções muito difíceis de serem tratadas, favorecendo a proliferação das bactérias.

A prescrição adequada dos antibióticos deve ser de forma racional, baseado em resultados laboratoriais, e não apenas em dados epidemiológicos de determinados agentes etiológicos responsáveis por certas infecções, como ocorre normalmente, o que leva a um consumo desnecessário e excessivo, tornando propício o desenvolvimento de resistência, e, por conseguinte, levando a problemas no tratamento de doenças infecciosas (DEL FIOL et al., 2010).

Estudos têm demonstrado que o uso de antimicrobianos em hospitais tem sido considerado inapropriado, desnecessário ou excessivo (RODRIGUES; BERTOLDI, 2010). Segundo a Organização Mundial de Saúde (OMS), o uso inadequado dos medicamentos tem as seguintes características: prescrições em excesso, omissão da prescrição, dose inadequadas, duração inapropriada, seleção inadequada, gasto desnecessário e risco desnecessário. A prioridade é evitar o desastre nas próximas 24 horas, resultado supostamente alcançado com antibióticos de amplo espectro ou o uso de vários antibióticos de pequeno espectro associados. Outro fato comum é o repetimento automático das prescrições, fazendo com que a duração do tratamento se prolongue para além do necessário. A gravidade das infecções também favorece o uso empírico dos antimicrobianos, podendo desencadear a seleção de cepas resistentes (WANNMACHER, 2004).

As aplicações dos antimicrobianos são definidas com base no conhecimento do micro-organismo infectante e no tipo de atividade pretendida, se curativa ou profilática. A terapia curativa tem como finalidade a cura da doença estabelecida, ou combater de um agente infeccioso situado em um determinado local. O uso profilático é aceito quando se deseja prevenir uma infecção em situações da qual há risco elevado, obedecendo a critérios bem definidos de análise de benéfico para a sua instalação (CFF, 2006). A terapia antimicrobiana pode ser específica ou presuntiva. A específica é executada mediante a identificação do agente infeccioso, através de testes laboratoriais; a presuntiva é guiada pelo possível micro-organismo, prevalente no determinado tipo de manifestação clínica. A terapia específica é o procedimento preferencial, porém, na prática clínica, observa-se um uso desnecessário e abusivo na terapia presuntiva (CFF, 2006; CARNEIRO et al., 2011).

A OMS preconiza como uso apropriado de antimicrobianos, o uso eficaz em relação ao custo com o qual se obtém o máximo de efeito terapêutico e com o mínimo de toxicidade e potencial de desenvolvimento de resistência microbiana (TAVARES; BERTOLDI; MUCCILO-BAISH, 2008).

O grande responsável pela disseminação dos genes de resistência é o próprio homem (DEL FIOL, 2010). Condutas como associações não embasadas na literatura, trocas frequentes de antimicrobianos, dose, posologia e tempo de tratamento inadequado, são fatores que levam a seleção de bactérias resistentes (SILVA, 2012).

Maier e Abegg (2007), recomendam que o uso de um antimicrobiano só deve ser feito após a realização de um antibiograma, para que o uso seja racional, justificando que a não identificação do patógeno pode mascarar o diagnóstico, causar toxicidade grave, e selecionar micro-organismos resistentes. Porém, como nem sempre a identificação do patógeno é possível, a escolha do antimicrobiano deve-se considerar o local de ação, a microbiota bacteriana normal presente neste e os prováveis agentes etiológicos. Abrantes et al. (2007), alertam que não basta apenas o diagnóstico preciso e a seleção adequada do antimicrobiano se a prescrição não for rigorosamente elaborada e completa em todos os seus aspectos.

A utilização de antimicrobianos varia consideravelmente de hospital para hospital. Cerca de $40 \%$ dos pacientes hospitalizados são tratados com antimicrobianos (RODRIGUES; BERTOLDI, 2010). Um estudo realizado em um hospital do Rio Grande do Sul, através de análise de prontuários, demonstrou que $15,8 \%$ dos pacientes receberam antimicrobianos, com uma média de internação de 10 dias. A média de idade dos pacientes foi de 39,5 anos. As principais indicações de antimicrobianos foram para infecções de vias aéreas e profilaxia cirúrgica. $\mathrm{O}$ grupo das cefalosporinas foi os medicamentos mais utilizados $(22,4 \%)$ (CARNEIRO et al., 2011). Já outro estudo realizado em um hospital privado também no Rio Grande do Sul, mostrou que a prevalência do uso de antimicrobianos foi em 52,4\% dos pacientes, e a média de internação foi de 14 dias, sendo a média de idade de 52,6 anos, sendo as cefalosporinas também o grupo mais utilizado (43,4\%) (RODRIGUES; BERTOLDI, 2010). Comparando os dois estudos, observa-se que no primeiro, o 
consumo foi menor, e, por conseguinte, o tempo de internação também foi menor. Porém, na classe de medicamentos utilizados, nos dois hospitais a prevalência na prescrição foram as cefalosporinas, o que já é esperado, por se tratar de uma classe de antimicrobianos com baixa toxicidade e ótima segurança, apesar de estar associada à resistência bacteriana.

A Klebsiella pneumoniae Carbapenemase (KPC) constitui importante mecanismo de resistência no contexto hospitalar mundial. A produção da enzima KPC se caracteriza por conferir resistência a todos os antibióticos $\beta$-lactâmicos. Esta característica, juntamente ao fato de ser uma enzima codificada por plasmídeos móveis, facilita a transferência do gene inter-espécies e agrava de forma significativa as consequências de sua disseminação. As KPC podem causar uma série de infecções, que variam desde infecções urinárias, gastroenterites e pneumonias até meningites e bacteremia. As espécies de importância clínica compreendem Escherichia coli, Klebsiella spp., Enterobacter spp., Serratia marcescens, Proteus spp., Morganella spp., Providencia spp., Shigella spp. e Salmonella spp., dos quais alguns estão entre os dez no ranking dos principais micro-organismos associados a infecções hospitalares (RIBEIRO, 2013).

Um estudo realizado em um hospital no sul do Brasil, entre 2009 e 2012, mostrou que 77 pacientes apresentaram exame clínico positivo para enterobactéria produtora de KPC. Desses pacientes, 41 (53\%) foram isolados K. pneumoniae. O período de internação transcorreu entre 9 e 87 dias. Os antimicrobianos que destacaram com maior sensibilidade foram Amicacina (97,5\%) e Gentamicina (70\%). Nenhum desses antimicrobianos tem ação adequada em infecções sistêmicas graves, quando usados sozinhos. Dos 77 pacientes estudados, 32 (41,5\%) evoluíram para óbito, evidenciando a alta morbi-mortalidade associada (ALVES; BEHAR, 2013). Em um hospital de Porto Alegre, foram analisadas 30 cepas. Dessas, 21 cepas $(70 \%)$ eram $K$. pneumoniae (DIENSTMANN et al., 2010). Comparando os dois estudos, nota-se que a prevalência de infecções são por K. pneumoniae é alta.

Outra bactéria de grande importância hospitalar é o Staphylococcus aureus. Ele é encontrado colonizando a microbiota natural, principalmente da pele, podendo tornar-se patogênico em condições como a quebra da barreira cutânea ou diminuição da imunidade, causando uma grande variedade de infecções, como na pele, infecções pós cirúrgicas, osteomielites, pneumonias, abscessos, endocardites e bacteremias. Devido a produção de betalactamases, o $S$. aureus inativa quase todas as penicilinas, com isso em 1960 foi descoberto outra penicilina, a meticilina, que não era suscetível a ação das betalactamases. Porém, em 1970 começou o aparecimento de cepas resistentes denominadas como MRSA $(S$. aureus resistentes a meticilina). As cepas MRSA se disseminaram rapidamente no ambiente hospitalar, limitando a antibioticoterapia apenas com vancomicina e teicoplanina. Atualmente, os índices de cepas MRSA resistentes em hospitais brasileiros variam de $40 \%$ a $80 \%$, principalmente em unidades de terapia intensiva (SANTOS et. al., 2007). Fatores como mortalidade e custo atribuído a essas cepas, reforçam a necessidade de implementação de programas de vigilância microbiológica ativa. A atuação das comissões de controle de infecções hospitalares $(\mathrm{CCIH})$ também é importante, pois além de normatizadora, estabelecendo regras para os profissionais de saúde na excussão de suas atividades, também promove a vigilância e ações educativas para a difusão de conhecimentos, apresentando como objetivo o oferecimento de condições de segurança aos pacientes e colaborares das instituições (SILVA, 2008; FERREIRA; BEZERRA, 2010).

Berquó et al. (2004), destacam que dentre as estratégias adotadas para o manejo desse grave problema de saúde pública, três formas de atuação têm sido propostas: a caracterização das práticas atuais, por meio de estudos junto aos prestadores de cuidados, em relação aos seus hábitos de prescrição; a criação de guias e protocolos para o uso racional de antimicrobianos; e, finalmente, o desenvolvimento de materiais e estratégias educacionais (para médicos e usuários), visando alterar hábitos e comportamentos.

\section{Considerações Finais}

O uso indevido de antibióticos vem crescendo assim como o desenvolvimento de cepas microbianas resistentes a estes fármacos. Uma questão preocupante, pois apesar do grande arsenal disponível dessas drogas, muitas já não apresentam resposta frente à determinadas infecções o que compromete o tratamento e coloco em risco a vida do paciente. Os fatores que levam a não efetividades do tratamento com antimicrobiano se devem a diversas razões como, prescrição inadequada, erro na dose, posologia e/ou tempo de tratamento, escolha inapropriada entre outros. Dessa forma, é necessário o trabalho de conscientização com prescritores e usuários, bem como, a produção de protocolos para a escolha adequada dos agentes antimicrobianos, tanto em ambientes hospitalares quanto ambulatoriais.

\section{Referências}

ABRANTES, P. M. et al. Avaliação da qualidade das prescrições de antimicrobianos dispensadas em unidades publicas de saúde de Belo Horizonte, Minas Gerais, Brasil, 2002. Cad. Saúde Pública, Rio de Janeiro, v. 23, n. 1, p. 95-104, 2007.

ALVES, P. A.; BEHAR, P. R. P. Infecções hospitalares por enterobactérias produtoras de KPC em um hospital terciário do sul do Brasil. Rev. AMRIGS, Porto Alegre, v. 57, n. 3, p. 213-218, 2013.

ANVISA - Agência Nacional de Vigilância Sanitária - . Mecanismos de resistência bacteriana aos antimicrobianos. 2007. Disponível em: <http://www.anvisa.gov.br/ servicosaude/controle/rede_rm/cursos/rm_controle/opas web/modulo3/mecanismos. $\overline{h t m}>$ acesso em 12 de set. 2016 .

BERQUÓ, L. S. et al. Utilização de antimicrobianos em uma população urbana. Rev. Saúde Pública, São Paulo, v. 38 , n. 2, p. 239-246, 2004

CARNEIRO, M. et al. O uso de antimicrobianos em um hospital de ensino: uma breve avaliação. Rev. Assoc. Med. Bras., São Paulo, v. 57, n. 4, p. 421-424, 2011.

CFF - Conselho Federal de Farmácia. Centro Brasileiro de Informação sobre medicamentos. Ações que estimulam o uso racional de antimicrobiano. Brasília, n. 4, 2006. 
DEL FIOL, F. de S. et al. Perfil de prescrições e uso de antibióticos em infecções comunitárias. Rev. Soc. Bras. Med. Trop., Uberaba, v.43 n. 1, p. 68-72, 2010.

DIENSTMANN, R. et al. Avaliação fenotípica da enzima Klebsiella pneumoniae carbapenemase (KPC) em Enterobacteriaceae de ambiente hospitalar. J. Bras. Patol. Med. Lab., Rio de Janeiro, v. 46, n.1, 2010.

FERRAREZE, M. V. G. et al. Pseudomonas aeruginosa multirresistente em unidade de cuidados intensivos: desafios que procedem. Acta Paul. Enferm., São Paulo, v. 20, n. 1 p. 7-11, 2007.

FERREIRA, R. S., BEZERRA, C. M. F. Atuação da comissão de controle de infecção hospitalar (CCIH) na redução da infecção: um estudo no hospital da criança Santo Antônio. Norte Científico, v. 5, n. 1, p. 29-45, 2010.

JACOBY, T. S. Associação entre o consumo de antimicrobianos e multirresistência bacteriana em Centro de Terapia Intensiva de Hospital Universitário Brasileiro, 2004 - 2006. 2008. 108 f. Dissertação (Mestrado em Medicina) - Universidade Federal do Rio Grande do Sul, Porto Alegre, 2008.

KADOSAKI, L. L, SOUSA, S. F., BORGES, J. C. M. Análise do uso e da resistência bacteriana aos antimicrobianos em nível hospitalar. Rev. Bras. Farm., Rio de Janeiro, v. 93, n. 2, p. 128-135, 2012.

MACHADO-ALBA, J. E.; GONZALES-SANTOS, D. M. Dispensación de antibióticos de uso ambulatório en una población colombiana. Rev. Saúde. Pública, Bogotá, v. 11, n. 5, p. 734-744, 2009.

MAIER, C. R.; ABEGG, M. A. Avaliação da utilização de antibióticos por profissionais de saúde e pela população da cidade de Toledo, Paraná, Brasil. Arq. Ciênc. Saúde Unipar, v. 11, n. 1, p. 19-26, 2007.

MOTA, R. A. et al. Utilização indiscriminada de antimicrobianos e sua contribuição a multirresistência bacteriana. Braz. J. Resanim, São Paulo, v. 42, n. 6, p. 465470, 2005.

ONZI, P. S.; HOFFMAN, S. P.; CAMARGO, A. L.

Avaliação do consumo de antimicrobianos injetáveis de um hospital privado no ano de 2009. Rev. Bras. Farm. Hosp. Serv. Saúde, São Paulo, v. 2, n. 2, p. 20-25, 2011.

RIBEIRO, B. V. Detecção de resistência aos carbapenêmicos e avaliação da produção de Klebsiella pneumoniae Carbapenemase (KPC) em isolados clínicos da família Enterobacteriaceae. 2013. 134 f. Tese (Doutorado em Ciências Farmacêuticas) - Universidade Federal do Rio Grande do Sul, Porto Alegre, 2013.

ROCHA, M. A.; CARNEIRO, P. M.; CASTILHO, S. R. Estudo da utilização de medicamentos antimicrobianos de 2003 a 2004 em pacientes adultos em hospital terciário no
Rio de Janeiro. Rev. Bras. Farm., Rio de Janeiro, v. 90, n. 1, p. 50-53, 2009.

RODRIGUES, F. D.; BERTOLDI, A. D. Perfil da utilização de antimicrobianos em um hospital privado. Ciênc. Saúde coletiva, Rio de Janeiro, p. 1239-1247, 2010.

SANTOS, A. L. et al. Staphylococcus aureus: visitando uma cepa de importância hospitalar. Bras. Patol. Me. Lab., Niterói, v. 43, n. 6, p. 413-423, 2007.

SILVA, E. R. M. Análise do perfil das prescrições de antimicrobianos na clínica médica de um hospital público do Pará. Rev. Bras. Farm. Hosp. Serv. Saúde. São Paulo, v. 3, n. 2, p. 15-19, 2012.

SILVA, E. U. A importância do controle da prescrição de antimicrobianos em hospitais para melhoria da qualidade, redução dos custos e controle da resistência bacteriana. Prática Hospitalar. v. 10, n. 57, p. 101-106, 2008.

TAVARES, N. U. L.; BERTOLDI, A. D; MUCCILLOBAISCH, A. L. Prescrição de antimicrobianos em unidades de saúde da família no Sul do Brasil. Cad. Saúde Pública, Rio de Janeiro, v. 24, n.8, p. 1791-1800, 2008.

WANNMACHER, L. Uso indiscriminado de antibióticos e resistência microbiana: uma guerra perdida? Uso racional de medicamentos: temas selecionados, Brasília, v. 1, n. 4, p. 1-6, 2004. 